\title{
Valor nutritivo do capim-andropogon em quatro idades de rebrota em período chuvoso
}

\author{
Nutritional value of andropogon grass in four regrowth ages during rain session
}

\author{
SILVA, Daniel Cézar da ${ }^{1 *}$; ALVES, Arnaud Azevêdo ${ }^{2}$; LACERDA, Marlúcia da Silva \\ Bezerra $^{3}$; MOREIRA FILHO, Miguel Arcanjo ${ }^{4}$; OLIVEIRA, Maria Elizabete de ${ }^{2}$; \\ LAFAYETTE, Elizabeth Almeida ${ }^{5}$
}

\author{
${ }^{1}$ Instituto Federal da Paraíba, Unidade São Gonçalo, Sousa, Paraíba, Brasil \\ ${ }^{2}$ Universidade Federal do Piauí, Centro de Ciências Agrárias, Departamento de Zootecnia, Teresina, \\ Piauí, Brasil \\ ${ }^{3}$ Instituto Federal do Piauí, Teresina, Piauí, Brasil \\ ${ }^{4}$ Universidade Federal do Piauí, Programa de Pós-Graduação em Ciência Animal, Teresina, Piauí, Brasil \\ ${ }^{5}$ Universidade Federal de Pernambuco, Departamento de Antibióticos, Recife, Pernambuco, Brasil \\ *Endereço para correspondência: danielcezar.s@ig.com.br
}

\section{RESUMO}

Objetivou-se avaliar o efeito da idade após rebrota $(35,49,63$ e 77 dias) sobre a relação folha/colmo, composição bromatológica, produtividade $\mathrm{e}$ degradabilidade in situ do capim-andropogon (Andropogon gayanus Kunth.). Houve efeito linear crescente $(\mathrm{P}<0,01)$ dos dias de crescimento sobre os teores de MS e FDA na planta e de FDN e FDA nas folhas e decrescente para PB e MM na planta. Houve efeito quadrático $(\mathrm{P}<0,01)$ para teores de FDN na planta, PB nas folhas e relação folha/colmo. A produtividade foi influenciada $(\mathrm{P}<0,01)$, com acréscimo de $0,0388 \mathrm{t}$ de $\mathrm{MS}_{\mathrm{h}} \mathrm{ha}^{-1}$ por dia de crescimento. A degradabilidade potencial da MS e FDN foram elevadas aos 35 dias após rebrota, nos três tempos de incubação, com decréscimos em função da elevação da idade de rebrota. Aos 35 e 63 dias após rebrota, verificou-se maior degradabilidade potencial da PB. A degradação efetiva da MS foi elevada aos 35 dias, enquanto para FDN maiores valores foram verificados aos 35 e menores aos 77 dias. O capim-andropogon, no intervalo de 35 a 49 dias após rebrota, apresenta maior degradabilidade potencial e degradação efetiva da matéria seca, proteína bruta e fibra em detergente neutro, decorrente da melhor relação folha/colmo associado ao menor teor de fibra, além de apresentar teor proteico 6 a $8 \%$, suficiente à mantença de ruminantes.

Palavras-chave: Andropogon gayanus, composição bromatológica, degradabilidade in situ, gramínea tropical, produtividade

\section{SUMMARY}

It was evaluated the effect of four regrowth ages (35, 49, 63 and 77 days) on leaf/steam relation, bromatological composition, productivity and in situ degradability of Andropogon grass (Andropogon gayanus Kunth.) during rain session. There was linear effect increasing $(\mathrm{P}<.01)$ of ages after regrowth for $\mathrm{DM}$ and $\mathrm{ADF}$ in plant and for $\mathrm{NDF}$ and ADF in leaves and decreasing for $\mathrm{CP}$ and $\mathrm{MM}$ plant. There was quadratic effect $(\mathrm{P}<.01)$ for NDF in the plant, CP in leaf and for leaf/stem relation. Productivity was influenced $(\mathrm{P}<.01)$, with increase of $38.8 \mathrm{~kg}$ of DM for day after regrowth. DM and NDF potential degradability were high at 35 days after regrowth, in three incubation times, with decreases due to the increase of age of regrowth At 35 and 63 days after regrowth was verified the greater $\mathrm{CP}$ potential degradability. Effective degradation of DM was high at 35 days after regrowth, while for NDF higher values were obtained at 35 and minor to 77 days. Andropogon grass to 35 at 49 regrowth days, has higher potential degradability and effective degradability of dry matter, crude protein and neutral detergent fiber, due to better leaf/stem ratio associated with lower fiber content, and presenting 6 to $8 \%$ of protein content, enough to maintenance of ruminants.

Keywords: Andropogon gayanus, bromatological composition, in situ degradability, tropical grass, productivity 


\section{INTRODUÇÃO}

As forragens têm papel fundamental na nutrição de animais ruminantes, como fonte de energia de menor custo em relação aos concentrados e por fornecerem fibra necessária à manutenção da função ruminal, determinante do consumo de matéria seca e da produção animal.

A determinação do valor nutritivo de forragens constitui premissa para conhecer o que a forrageira está suprindo em nutrientes ao animal. Este conceito apresenta maior importância em se tratando de gramíneas tropicais, como o capim-andropogon (Andropogon gayanus Kunth.), largamente utilizado em áreas de caatinga, cerrado e mata de cocais, nos estados do Maranhão, Tocantins e Piauí. O capim-andropogon é uma gramínea de origem africana, perene, com porte de 1,5 a $2,5 \mathrm{~m}$ de altura, com boa adaptação a regiões secas, de solos arenosos ácidos com baixa fertilidade, sendo apetitosa e nutritiva quando jovem, mas produz inflorescência de talos duros e pouco aceito por ruminantes com o avançar do estádio vegetativo (FAO, 2004).

$\mathrm{Na}$ determinação do valor nutritivo de forragens são empregados dados referentes à composição química, associados à degradabilidade ruminal e digestibilidade que, junto à disponibilidade da forragem, tem grande efeito sobre o consumo. Segundo Clipes et al. (2010), o conhecimento mais detalhado da extensão e da taxa de degradação dos nutrientes representa o novo panorama da nutrição animal, pois permite agregar às atuais estratégias alimentares, os conceitos de pecuária de precisão, que visam maximizar os ganhos de produção, sobretudo em ruminantes terminados a pasto.
Os estudos da dinâmica digestiva em ruminantes têm permitido identificar fatores que afetam o consumo voluntário de forragens, tais como o grau de maturidade das plantas, relação folha/colmo ou a forma de processamento do alimento. A avaliação da degradação ruminal de forragens em diferentes idades após rebrota permite não só a comparação entre diferentes espécies, mas também o estudo do melhor estádio de maturação para sua utilização (RODRIGUES et al., 2004).

De acordo com Costa et al. (2011), o acúmulo de forragem de uma gramínea está estreitamente relacionado ao seu estádio de crescimento, como decorrência das alterações morfológicas e fisiológicas que afetam o balanço entre a produção e senescência de tecidos, com reflexos na composição química, capacidade de rebrota e persistência da pastagem.

Objetivou-se avaliar a produtividade, composição bromatológica e degradabilidade in situ dos nutrientes do capim-andropogon em quatro idades após rebrota em período chuvoso.

\section{MATERIAL E MÉTODOS}

O experimento foi conduzido no Setor de Caprinocultura do Departamento de Zootecnia (DZO), no Centro de Ciências Agrárias (CCA) da Universidade Federal do Piauí (UFPI), em Teresina, estado do Piauí, localizado em latitude $05^{\circ} 05^{\prime} 21^{\prime \prime} \mathrm{S}$, longitude $42^{\circ} 48^{\prime} 07^{\prime \prime} \mathrm{W}$ e altitude de $74,4 \mathrm{~m}$, com pluviosidade acumulada no período $801,6 \mathrm{~mm}$, temperatura média de $30^{\circ} \mathrm{C}$ e umidade relativa do ar $62,5 \%$. O solo da área apresentava a seguinte composição química nos $20 \mathrm{~cm}$ superficiais: $\mathrm{pH}$ em $\mathrm{H}_{2} \mathrm{O}=5,05 ; \mathrm{P}=2,33 \mathrm{mg} / \mathrm{dm}^{3} ; \mathrm{Ca}=$ $1,5 \mathrm{cmol}_{\mathrm{C}} / \mathrm{dm}^{3} ; \mathrm{Al}=0,12 \mathrm{cmol}_{\mathrm{C}} / \mathrm{dm}^{3} ; \mathrm{K}=$ 
Rev. Bras. Saúde Prod. Anim., Salvador, v.15, n.3, p.626-636 jul./set., 2014 http://www.rbspa.ufba.br ISSN 15199940

$35,77 \mathrm{cmol}_{\mathrm{c}} / \mathrm{dm}^{3} ; \mathrm{Mg}=0,61 \mathrm{cmol}_{\mathrm{C}} / \mathrm{dm}^{3}$; e Matéria orgânica $=1,12 \mathrm{~g} / \mathrm{kg}$.

Conforme o sistema de Köppen, a região é classificada como Aw-Tropical Chuvoso de Savana, com inverno seco (junho a novembro) e verão chuvoso (dezembro a maio), e a maior precipitação pluviométrica se concentra nos meses de janeiro a abril e os máximos de deficiência hídrica ocorrem entre os meses de outubro a novembro.

A área experimental foi constituída por monocultivo de capim-andropogon (Andropogon gayanus Kunth.), não irrigado, subdividida em 20 parcelas de $15 \mathrm{~m}^{2}$ cada, totalizando área de $300 \mathrm{~m}^{2}$. As amostras de capim-andropogon foram coletadas após corte de uniformização, aos 35, 49, 63 e 77 dias após rebrota, a altura de $10 \mathrm{~cm}$ do solo, com auxílio de quadro com área útil de $1,0 \mathrm{~m}^{2}$, deixando-se bordadura de $0,5 \mathrm{~m}$, segundo o delineamento inteiramente casualizado com quatro tratamentos (35, 49, 63 e 77 dias após rebrota) e cinco repetições.

O material coletado foi subdividido em dois tipos de amostras: plantas inteiras, lâminas foliares e colmos, sendo encaminhadas ao Laboratório de Nutrição Animal DZO/CCA/UFPI, para determinação da composição bromatológica.

As amostras foram pré-secas em estufa com circulação forçada de ar a $55^{\circ} \mathrm{C}$, por $72 \mathrm{~h}$, moídas em moinho tipo Willey com peneira de malha $1,0 \mathrm{~mm}$ para a composição bromatológica e a 2,0mm para a degradabilidade in situ. Procedeu-se análise dos teores de matéria seca (MS), e com base na MS, nitrogênio $(\mathrm{N})$ pelo processo semimicro kjeldahl, com estimativa do teor de proteína bruta $(\mathrm{PB}=\mathrm{N} \times 6,25)$, nitrogênio insolúvel em detergente neutro (NIDN), nitrogênio insolúvel em detergente ácido (NIDA) e matéria mineral (MM), segundo metodologias descritas por Silva \& Queiroz (2002), e fibra em detergente neutro (FDN) e fibra em detergente ácido (FDA), segundo o método de Van Soest, adaptado por Souza et al. (1999). Os dados da composição bromatológica do capim-andropogon em função das idades após rebrota estão apresentados na Tabela 1 .

Tabela 1. Composição bromatológica do capim-andropogon em quatro idades após rebrota

\begin{tabular}{lcccc}
\hline \multirow{2}{*}{ Nutriente } & \multicolumn{4}{c}{ Idades de rebrota (dias) } \\
\cline { 2 - 5 } & 35 & 49 & 63 & 77 \\
\hline Matéria seca (MS \%) & 26,01 & 29,34 & 28,02 & 33,39 \\
\hline \% na MS* & & & \\
\hline Proteína bruta & 8,49 & 6,36 & 4,96 & 3,63 \\
Fibra em detergente neutro & 68,33 & 70,81 & 73,50 & 75,94 \\
Fibra em detergente ácido & 35,55 & 40,04 & 41,03 & 45,89 \\
Matéria mineral & 6,21 & 5,12 & 5,55 & 4,44 \\
\hline \% do nitrogênio (N) total & \multicolumn{4}{c}{38,23} \\
\hline N insolúvel em detergente neutro & 46,71 & 40,45 & 49,58 \\
N insolúvel em detergente ácido & 8,41 & 10,20 & 11,29 & 24,12 \\
*MS = matéria seca. & & &
\end{tabular}


Para realização do ensaio de degradação, utilizou-se um bovino macho adulto, mestiço da raça Holandesa, com peso corporal de $450 \mathrm{~kg}$, alojado em baia individual e provido de cânula ruminal, mantido em sistema de alimentação com dieta formulada segundo National Research Council (2001), visando-se atendimento às exigências nutricionais de mantença, fornecida às 8 e 16h, além de água e mistura mineral completa $a d$ libitum.

As incubações in situ foram realizadas utilizando-se sacos de náilon de dimensões $8 \times 12 \mathrm{~cm}$ e porosidade $50 \mu \mathrm{m}$, os quais foram pesados e introduziu-se $4 \mathrm{~g}$ de amostra de capim seca ao ar por saco. Os sacos foram incubados no ambiente ruminal do bovino nos tempos 6, 24 e $72 \mathrm{~h}$, em triplicata, de forma sequenciada, iniciando-se pelo maior tempo de incubação, suspensos por fio de náilon de $50 \mathrm{~cm}$, com a extremidade fixada à cânula e distribuídos na porção ventral do rúmen, ancorados por um peso de $0,5 \mathrm{~kg}$, segundo recomendações de Alves et al. (2007).

Após desincubados, os sacos foram imediatamente colocados em água gelada para paralisação do processo fermentativo e remoção de partículas aderidas externamente aos mesmos, sendo lavados em máquina de lavar com água corrente, até que esta se mostrasse límpida.

Após a lavagem, os sacos contendo os resíduos foram secos em estufa com circulação forçada de ar a $55^{\circ} \mathrm{C}$, por $72 \mathrm{~h}$, sendo posteriormente determinados os pesos secos dos sacos contendo as amostras residuais. Os resíduos de degradação foram analisados para teores de MS e PB, de acordo com Silva \& Queiroz (2002), e de FDN, segundo Van Soest, adaptado por Souza et al. (1999).

A fração prontamente solúvel (fração $a$ ) foi determinada de acordo com procedimento adotado para os sacos incubados, conforme descrito por Fathi et al. (2006).
Os parâmetros de degradação in situ e a degradabilidade potencial $(\mathrm{P})$ foram estimados segundo o modelo proposto Ørskov \& McDonald (1979), simplificado por Sampaio (1995), $\mathrm{P}=\mathrm{A}-\mathrm{Be}^{\text {-ct }}$. A degradabilidade efetiva (DE) foi calculada pela equação proposta por Ørskov \& McDonald (1979), DE = a $+[(\mathrm{bc}) /(\mathrm{c}+\mathrm{k})]$, considerando $\mathrm{k}=5 \% / \mathrm{h}$.

Foram realizadas estatísticas descritivas para média, desvio padrão e coeficiente de variação, segundo o PROC MEANS para todos os parâmetros. Para os parâmetros relação folha/colmo, composição bromatológica e produtividade, realizaram-se análise de regressão por meio do procedimento PROC REG, enquanto os parâmetros de degradabilidade foram analisados utilizando-se os procedimentos PROC GLM, comparando-se os valores médios pelo teste Student-Newman-Keuls (SNK), com obtenção dos parâmetros não lineares $a, b$ e $c$ pelo método interativo de Gauss-Newton do PROC NLIN. Em todos os procedimentos adotou-se o logiciário estatístico SAS (STATISTICAL ANALYSIS SYSTEM INSTITUTE, 2000).

\section{RESULTADOS E DISCUSSÃO}

Houve efeito linear positivo $(\mathrm{P}<0,01)$ dos dias de crescimento após rebrota do capim-andropogon para teores de matéria seca (MS) e fibra em detergente ácido (FDA) na planta e para fibra em detergente neutro (FDN) e FDA nas folhas e, negativo $(\mathrm{P}<0,01)$ para proteína bruta $(\mathrm{PB})$ e matéria mineral (MM) na planta. Os teores de FDN na planta, PB nas folhas e relação folha/colmo resultaram em efeito quadrático $(\mathrm{P}<0,01)$. Não houve efeito significativo $(\mathrm{P}>0,05)$ para teor de MM nas folhas, com média 5,74 $\pm 1,11$ (Tabela 2). 
Rev. Bras. Saúde Prod. Anim., Salvador, v.15, n.3, p.626-636 jul./set., 2014 http://www.rbspa.ufba.br ISSN 15199940

Tabela 2. Relação folha/colmo, constituintes bromatológicos na planta e folhas, e produtividade do capim-andropogon em quatro idades de rebrota

\begin{tabular}{|c|c|c|c|c|c|c|}
\hline \multirow{2}{*}{ Parâmetros } & \multicolumn{4}{|c|}{ Dias após rebrota } & \multirow{2}{*}{$\begin{array}{l}\text { Equação de } \\
\text { regressão }\end{array}$} & \multirow{2}{*}{$\mathrm{CV}(\%)$} \\
\hline & 35 & 49 & 63 & 77 & & \\
\hline $\begin{array}{l}\text { Relação } \\
\text { folha/colmo }\end{array}$ & 0,77 & 0,47 & 0,28 & 0,21 & 1 & 19,75 \\
\hline \multicolumn{6}{|c|}{ Composição bromatológica } & \multirow[b]{2}{*}{7,19} \\
\hline MS planta (\%) & 26,08 & 28,16 & 30,24 & 32,32 & 2 & \\
\hline \multicolumn{7}{|l|}{$\%$ na MS } \\
\hline PB planta & 8,26 & 6,66 & 5,06 & 3,47 & 3 & 8,90 \\
\hline PB folhas & 9,56 & 7,22 & 6,01 & 5,94 & 4 & 8,47 \\
\hline FDN planta & 65,20 & 70,33 & 71,98 & 70,14 & 5 & 3,48 \\
\hline FDN folhas & 68,32 & 70,87 & 73,42 & 75,98 & 6 & 2,83 \\
\hline FDA planta & 35,64 & 37,28 & 38,93 & 40,57 & 7 & 4,11 \\
\hline FDA folhas & 35,44 & 39,22 & 43,01 & 46,79 & 8 & 3,87 \\
\hline MM planta & 6,11 & 5,18 & 4,24 & 3,31 & 9 & 8,11 \\
\hline \multicolumn{7}{|c|}{ Produtividade } \\
\hline MS t.ha ${ }^{-1}$ & 0,453 & 0,996 & 1,593 & 2,083 & 10 & 8,15 \\
\hline \multicolumn{7}{|c|}{$\begin{array}{l}\text { MS = Matéria seca; PB = Proteína bruta; FDN = Fibra em detergente neutro; FDA = Fibra em de } \\
\text { ácido; MM = Matéria mineral. }\end{array}$} \\
\hline
\end{tabular}

A relação folha/colmo resultou em valor mínimo, 0,21, aos 77 dias de rebrota, enquanto, aos 35 dias, verificou-se proporção de MS de folhas equivalente a 77,3\% da planta (Tabela 2). De acordo com Veras et al. (2010), a redução na relação folha/colmo quando do aumento da idade de rebrota é um comportamento normal para sistemas de monocultivo, uma vez que maiores intervalos de rebrota no manejo de gramíneas resultam em aumento do índice de área foliar e, assim, no autossombreamento dos perfilhos basais; a consequência é o alongamento do colmo.

Considerando-se que as maiores concentrações de PB estão contidas nas folhas, a utilização de capimandropogon em avançada idade após rebrota, na alimentação de ruminantes, pode resultar em baixo desempenho animal, como consequência do acréscimo da fração colmo na forragem produzida, que detém maiores teores das frações fibrosas da gramínea.

$\mathrm{O}$ teor de MS na planta aumentou em 0,15 unidades percentuais por dia de rebrota após corte, sendo este um comportamento normal para gramíneas tropicais, que em geral elevam o teor de MS em função do amadurecimento da gramínea. Ao avaliarem os teores de MS do capim-andropogon em sistema de monocultivo, Veras et al. (2010) também verificaram elevação destes, dos 35 aos 63 dias de rebrota.

$\mathrm{O}$ teor de $\mathrm{PB}$ na planta decresceu linearmente em 0,11 unidades percentuais por dia de rebrota após o corte (Tabela 2). A estimativa do teor de PB do capim-andropogon indica que aos 54,8 dias após rebrota o mesmo equivale a $6 \%$ na MS. Assim, entre 35 e 
55 dias verifica-se atendimento à faixa limite de 6 a $8 \%$ de PB na MS, abaixo da qual os microrganismos do rúmen teriam limitações de nitrogênio para degradação da fibra, como preconizado por Cavalcante et al. (2005) para bovinos de corte, o que demandaria suplementação proteica, inclusive para mantença.

Esta situação torna-se mais agravada ao se considerar o teor de PB nas folhas, que apresentou valor mínimo de 5,84\% na MS, aos 71 dias de rebrota (Tabela 2), o que associado à mínima relação folha/colmo, 0,21, verificada aos 77 dias de rebrota, pode representar fator de grande comprometimento do desempenho de animais ruminantes, visto que o teor apresentado situa-se abaixo do limiar mínimo exigido pelos microrganismos ruminais. Ao avaliarem a composição bromatológica do capimandropogon em diferentes idades de rebrota, sob copas de pau-d'arco (Tabebuia serratifolia Vahl.) e jatobá (Hymenaea courbaril L.) e em área aberta, Lacerda et al. (2009) verificaram, independente do ambiente, decréscimos de $17,62 \%$ de PB na planta, entre as idades de rebrota $35 \mathrm{e}$ 63 dias, enquanto para as folhas, o teor de PB do capim-andropogon, em área aberta, foi de $9,16 \%$ na MS.

Quanto à produtividade do capimandropogon, houve efeito linear $(\mathrm{P}<0,01)$, com acréscimo de $0,0388 \mathrm{t}$ de MS.ha $^{-1}$ por dia de rebrota após corte (Tabela 2). Apesar deste resultado, deve-se procurar estabelecer um equilíbrio entre a máxima produção de forragem e o valor nutritivo da mesma, pois, segundo Costa et al. (2007), o aumento do intervalo de cortes resulta em incremento na produção de MS, porém, paralelamente, há declínio no valor nutritivo da forragem produzida.

Desta forma, como pode ser constatado nesta pesquisa, a produção máxima de forragem não necessariamente resultou em disponibilidade de material de elevado valor nutritivo, uma vez que houve maximização da FDN na planta aos 63 dias, correspondente a um teor estimado deste constituinte de $71,98 \%$ na MS, e incrementos de 0,12 e 0,27 unidades percentuais por dia de rebrota nos teores de FDA da planta e folha, respectivamente (Tabela 2).

Estes aspectos tornam-se importantes, pois o teor de FDN na forragem é considerado fator determinante do desempenho, uma vez que está relacionado à ingestão de MS quando comparado a outros nutrientes encontrados nos alimentos. O conteúdo de FDN é o melhor componente do alimento envolvido com a regulação da ingestão de MS em ruminantes.

Houve efeito das idades de rebrota $(\mathrm{P}<0,05)$ sobre a degradação ruminal da MS, PB e FDN do capim-andropogon, com valores superiores para médias de degradação ruminal aos 35 dias, à exceção da degradação da PB a degradação aos 35 dias foi assemelhado à obtida aos 49 dias $(\mathrm{P}>0,05)$. Entre os 49 e 63 dias após rebrota, não foi constatado diferença $(\mathrm{P}>0,05)$ para as médias de degradação dos nutrientes avaliados, contudo, dos 63 aos 77 dias após rebrota, verificou-se menor $(\mathrm{P}<0,05)$ degradação ruminal dos nutrientes na maior idade de rebrota, exceto para degradação da $\mathrm{PB}$ que não diferiu $(\mathrm{P}>0,05)$ no referido intervalo (Tabela 3).

De acordo com Rodrigues et al. (2004), com a elevação da idade de crescimento é comum haver comprometimento da degradação ruminal dos nutrientes, em virtude da lignificação dos tecidos da planta, o que associado à redução no teor proteico, pode comprometer o crescimento microbiano, diminuindo assim a eficiência do processo fermentativo ruminal. 
Rev. Bras. Saúde Prod. Anim., Salvador, v.15, n.3, p.626-636 jul./set., 2014 http://www.rbspa.ufba.br ISSN 15199940

Tabela 3. Degradação ruminal (\%) da matéria seca, proteína bruta e fibra em detergente neutro do capim-andropogon em quatro idades após rebrota

\begin{tabular}{lccc}
\hline \multirow{2}{*}{ Dias após rebrota } & \multicolumn{3}{c}{ Degradação ruminal (\%) } \\
\cline { 2 - 4 } & Matéria seca & Proteína bruta & Fibra em detergente neutro \\
\hline 35 & $51,55^{\mathrm{a}^{\mathrm{y}}}$ & $45,92^{\mathrm{a}}$ & $34,65^{\mathrm{a}}$ \\
49 & $47,45^{\mathrm{b}}$ & $40,77^{\mathrm{ab}}$ & $30,12^{\mathrm{b}}$ \\
63 & $45,20^{\mathrm{b}}$ & $36,66^{\mathrm{b}}$ & $28,17^{\mathrm{b}}$ \\
77 & $41,92^{\mathrm{c}}$ & $35,96^{\mathrm{b}}$ & $24,18^{\mathrm{c}}$ \\
\hline $\mathrm{CV}(\%)$ & 7,45 & 16,83 & 13,02 \\
\hline
\end{tabular}

*Médias seguidas por letras diferentes na mesma coluna diferem entre si, pelo teste $\mathrm{SNK}(\mathrm{P}<0,05)$. $\mathrm{CV}=$ Coeficiente de variação.

Como constatado nesta pesquisa, a maximização do teor de FDN na planta, $71,98 \%$ na MS, aos 63 dias após rebrota (Tabela 2), associado ao decréscimo de 0,11 unidades percentuais do teor de PB na planta em função dos dias de rebrota, contribuíram de sobremaneira para redução acentuada da degradação ruminal dos nutrientes do capim-andropogon.

Ressalta-se ainda que a elevação linear de 0,11 e 0,27 unidades percentuais do teor de FDA na planta e nas folhas do capim-andropogon, respectivamente, em função dos dias após rebrota (Tabela 2), também exerceu efeito sobre a degradação ruminal dos nutrientes, uma vez que esta fração mais lignificada dos tecidos da planta forma uma barreira impedindo a aderência e hidrólise enzimática microbiana.

Vasconcelos et al. (2009) afirmam que uma das principais razões para a diminuição da degradabilidade ruminal é o desbalanço de nutrientes, principalmente energia e proteína. Com o aumento da idade das plantas, além da elevação do teor de FDN, ocorre redução do teor de PB, o que pode acarretar a diminuição do aproveitamento da fibra em nível de rúmen.

Em relação aos parâmetros de degradação dos nutrientes do capim-andropogon, verificou-se para MS, fração solúvel $(a)$ com variação de 34,94 a 29,07\%, entre os
35 e 77 dias após rebrota (Tabela 4), sendo considerada elevada em relação à obtida por Cabral et al. (2005), 10,84\%, para o feno de capim-Tifton 85 aos 80 dias de rebrota, o que pode estar associado ao elevado teor de FDN da gramínea $(87,63 \%)$ quando comparado ao obtido nesta pesquisa $(75,98 \%)$ aos 77 dias de rebrota, fato que contribuiu para redução da fração prontamente utilizada pelos microrganismos ruminais.

A maior fração $a$ da PB foi $30,15 \%$, aos 63 dias após rebrota, bastante superior à obtida aos 77 dias (14,59\%). A fração $a$ da PB é de grande importância, por ser a fração prontamente utilizável pelos microrganismos ruminais e possibilitar imediata disponibilidade de nitrogênio aos mesmos, contribuindo com a síntese de proteína microbiana e para o aumento da eficiência de aproveitamento da fibra. $\mathrm{O}$ aumento da fração $a$, aos 63 dias após rebrota, está associado à redução do teor de NIDN $(38,23 \%)$ (Tabela 1), o que pode ser explicado pelo elevado índice pluviométrico verificado no período correspondente às idades 49 a 77 dias, induzindo à rebrota das plantas, com consequente aumento na quantidade de folhas jovens, as quais apresentam baixo teor de nitrogênio associado à fibra, estando este na forma amoniacal e, portanto, mais solúvel em água. 
Rev. Bras. Saúde Prod. Anim., Salvador, v.15, n.3, p.626-636 jul./set., 2014 http://www.rbspa.ufba.br ISSN 15199940

Tabela 4. Parâmetros de degradação ruminal, degradabilidade potencial (DP) para os tempos de incubação 6, 24 e 72 horas, e degradação efetiva (DE) da matéria seca, proteína bruta e fibra em detergente neutro do capim-andropogon em quatro idades após rebrota

\begin{tabular}{|c|c|c|c|c|c|c|c|c|}
\hline \multirow{2}{*}{$\begin{array}{l}\text { Dias após } \\
\text { rebrota }\end{array}$} & \multirow{2}{*}{$a(\%)^{1}$} & \multirow{2}{*}{$b(\%)^{2}$} & \multirow{2}{*}{$c(\% / h)^{3}$} & \multirow{2}{*}{$\mathrm{R}^{2}(\%)^{4}$} & \multicolumn{3}{|c|}{ DP } & \multirow{2}{*}{$\mathrm{DE}^{5}$} \\
\hline & & & & & 6 & 24 & 72 & \\
\hline \multicolumn{9}{|c|}{ Matéria seca } \\
\hline 35 & 34,94 & 50,22 & 2,81 & 95,99 & 37,36 & 56,33 & 77,68 & 53,01 \\
\hline 49 & 32,36 & 71,21 & 1,27 & 97,94 & 34,93 & 48,93 & 73,83 & 46,68 \\
\hline 63 & 31,94 & 44,38 & 2,15 & 87,83 & 34,64 & 48,01 & 66,24 & 45,28 \\
\hline 77 & 29,07 & 66,74 & 1,19 & 92,61 & 30,07 & 42,74 & 65,83 & 41,90 \\
\hline \multicolumn{9}{|c|}{ Proteína bruta } \\
\hline 35 & 27,96 & 72,61 & 2,07 & 95,07 & 25,52 & 48,87 & 81,43 & 49,22 \\
\hline 49 & 21,57 & 68,73 & 1,77 & 91,14 & 18,78 & 38,30 & 68,06 & 39,54 \\
\hline 63 & 30,15 & 39,18 & 1,86 & 73,82 & 35,65 & 45,23 & 59,46 & 40,78 \\
\hline 77 & 14,59 & 40,41 & 5,58 & 75,11 & 24,20 & 43,72 & 54,23 & 35,90 \\
\hline \multicolumn{9}{|c|}{ Fibra em detergente neutro } \\
\hline 35 & 11,43 & 70,85 & 2,72 & 96,90 & 15,07 & 41,09 & 71,12 & 36,39 \\
\hline 49 & 9,10 & 89,32 & 1,47 & 98,05 & 13,14 & 32,97 & 66,10 & 29,39 \\
\hline 63 & 9,49 & 63,94 & 1,93 & 92,24 & 14,48 & 31,78 & 56,94 & 27,29 \\
\hline 77 & 9,53 & 83,83 & 1,20 & 99,12 & 12,87 & 28,51 & 56,90 & 25,75 \\
\hline
\end{tabular}

${ }^{1} a=$ fração solúvel em água; ${ }^{2} b=$ fração insolúvel em água, mas potencialmente degradável $;{ }^{3} c=$ taxa de degradação da fração $b ;{ }^{4} \mathrm{R}^{2}=$ coeficiente de determinação; ${ }^{5}$ Taxa de passagem $\mathrm{k}=0,05 \mathrm{~h}^{-1}$.

Verificou-se maior valor da fração $a$ da FDN aos 35 dias após de rebrota, 11,43\%, e menor, 9,1\%, aos 49 dias após de rebrota, com estes próximos aos obtidos por Carvalho et al. (2006b), para os fenos dos capins-colonião, tifton e braquiária, 15,$35 ; 11,94$ e $9,89 \%$, respectivamente, com teores de FDN em torno de 72,66; 72,79 e $67,80 \%$ na MS, respectivamente. A diminuição da fração $a$ da FDN com a elevação da idade de rebrota caracteriza-se evento comum para gramíneas tropicais, que possuem rápido crescimento e lignificação dos tecidos.

Em relação à taxa de degradação $(c)$ dos nutrientes, verificou-se maior e menor valores aos 35 e 77 dias após rebrota, respectivamente, com exceção da taxa de degradação da PB aos 77 dias após rebrota, que foi de $5,58 \% / \mathrm{h}$, possivelmente atribuída à menor fração de nitrogênio associado à fibra decorrente da precipitação verificada no período correspondente às idades 49 a 77 dias.

Em média, a taxa $c$ obtida nesta pesquisa foi inferior às obtidas por Carvalho et al. (2006a), para MS e FDN do feno de capim-elefante, 4,3 e $3,9 \% / \mathrm{h}$, respectivamente, exceto para $\mathrm{PB}$, que mostrou-se semelhante $(2,26 \% / h)$. Os resultados mostraram-se mais condizentes com o valor de $c$ para o capim adropogon cv. Planaltina aos 63 dias de rebrota $(1,3 \% / \mathrm{h})$, obtido por Rodrigues et al. (2004).

A degradabilidade potencial da MS do capim-andropogon, foi elevada aos 35 dias após rebrota, nos três tempos de incubação, com decréscimos em função da elevação da idade de rebrota (Tabela 4). A degradação efetiva da MS, estimada para a taxa de passagem $(k) 5 \% / h$, foi maior aos 35 dias após rebrota, o que está 
associado à maior taxa de degradação $(c=$ $2,81 \% / \mathrm{h}$ ) nesta idade (Tabela 4).

A degradação efetiva da MS aos 63 dias após rebrota verificada nesta pesquisa $(45,28 \%)$, foi superior à obtida por Rodrigues et al. (2004) para capimandropogon cv. Planaltina em mesma idade após rebrota $(27,5 \%)$, o que está associado à baixa taxa de degradação ( $c=1,3 \% / \mathrm{h})$, em comparação ao valor verificado nesta pesquisa $(c=2,15 \% / \mathrm{h})$.

No tempo de incubação $24 \mathrm{~h}$, a maior degradabilidade potencial da PB foi obtida aos 35 e 63 dias após rebrota, enquanto às $72 \mathrm{~h}$ de incubação, o maior e menor valor foi obtido aos 35 e 77 dias, respectivamente (Tabela 4). A degradabilidade potencial da PB foi $\mathrm{o}$ parâmetro que apresentou maior oscilação dentro dos intervalos de rebrota estudados, com este comportamento possivelmente associado à grande translocação das proteínas do conteúdo celular em direção à parede celular, quando da maturação da gramínea.

Por outro lado, a maior degradabilidade potencial da PB obtida na incubação de $72 \mathrm{~h}$ para aos 63 e 77 dias de rebrota, 59,46 e $54,23 \%$, respectivamente pode estar associada à rebrota de algumas plantas, decorrente da elevação do índice pluviométrico no referido período.

A degradabilidade potencial da FDN foi maior aos 35 dias após rebrota, com decréscimo em função do aumento da idade de rebrota, com valor mínimo, $12,87 \%$, aos 77 dias de rebrota às $6 \mathrm{~h}$ de incubação. Quanto aos tempos de incubação, os maiores valores foram verificados às $72 \mathrm{~h}$, o que indica a necessidade de maior período de incubação para obtenção de maior degradabilidade potencial da fração fibrosa desta gramínea, independente da idade após rebrota.

Para degradação efetiva da FDN maior e menor valores foram verificados aos $35 \mathrm{e}$ 77 dias de rebrota, o que pode ser atribuído ao valor mínimo $(0,22)$ para relação folha/colmo aos 73 dias de rebrota, enquanto, aos 35 dias verificouse uma proporção de MS da folhas equivalente a $77,3 \%$ da planta. Dessa forma, percebe-se que à medida que a planta envelhece, ocorre aumento na proporção de colmo, consequentemente acompanhado pela elevação da deposição de lignina na parede celular, constituindo a fração insolúvel, como verificado por Rodrigues et al. (2004), o que resulta em potencial de degradação mais baixo, por ser este constituinte depressor à ação dos microrganismos ruminais.

O capim-andropogon, no intervalo de 35 a 49 dias após rebrota, apresenta maior degradabilidade potencial e degradação efetiva da matéria seca, proteína bruta e fibra em detergente neutro, decorrente da melhor relação folha/colmo associado ao menor teor de fibra, além de apresentar teor proteico 6 a $8 \%$, suficiente à mantença de ruminantes.

\section{REFERÊNCIAS}

ALVES, A.A.; SALES, R.O.; NEIVA, J.N.M.; MEDEIROS, A.N.; BRAGA, A.P.; AZEVEDO, A.R.

Degradabilidade ruminal in situ de vagens de faveira (Parkia platycephala

Benth.) em diferentes tamanhos de partículas. Arquivo Brasileiro de Medicina Veterinária e Zootecnia, v.59, n.4, p.1045-1051, 2007.

CABRAL, L.S.; FILHO, S.C.V.; ZERVOUDAKIS, J.T.; SOUZA, A.L.; DETMANN, E. Degradabilidade in situ da matéria seca, da proteína bruta e da fibra de alguns alimentos. Pesquisa Agropecuária Brasileira, v.40, n.8, p.777-781, 2005. 
Rev. Bras. Saúde Prod. Anim., Salvador, v.15, n.3, p.626-636 jul./set., 2014 http://www.rbspa.ufba.br ISSN 15199940

CARVALHO, G.G.P.; PIRES, A.J.V.; VELOSO, C.M.; DETMANN, E.; SILVA, F.F.; SILVA, R.R.

Degradabilidade ruminal do feno de alguns alimentos volumosos para ruminantes. Arquivo Brasileiro de Medicina Veterinária e Zootecnia, v.58, n.4, p.575-580, 2006a.

CARVALHO, G.G.P.; PIRES, A.J.V.; VELOSO, C.M.; SILVA, F.F.; SILVA, R.R. Degradabilidade ruminal do feno de forragens tropicais. Revista

Brasileira de Agrociência, v.12, n.1, p.81-85, 2006b.

CAVALCANTE, M.A.B.; PEREIRA, O.G.; VALADARES FILHO, S.C.; RIBEIRO, K.G.; CHIZZOTTI, F.H.M.; CLIPES, R.C.; SILVA, J.F.C.; DETMANN, E.; VÁSQUEZ, H.M.; HENRIQUES, L.T.; DONATELE, D.M. Associações entre parâmetros da cinética de degradação ruminal e os constituintes da parede celular de quatro gramíneas tropicais. Revista Brasileira de Saúde e Produção Animal [online], v.11, n.3, p.802-814, 2010.

COSTA, K.A.P.; OLIVEIRA, I.P.; FAQUIM, V.; NEVES, B.P.; RODRIGUES, C.; SAMPAIO, F.M.T. Intervalo de corte na produção de massa seca e composição químicobromatológica da Brachiaria brizantha cv. MG-5. Ciência e Agrotecnologia, v.31, n.8, p.1197-1202, 2007.

COSTA, N.L.; GIANLUPPI, V.; MORAES, A. Produtividade de forragem e morfogênese de Trachypogon vestitus em diferentes idades de rebrota nos cerrados de Roraima. Revista Brasileira de Saúde e Produção Animal[online], v.12, n.4, p.935-948, 2011.
FOOD AND AGRICULTURE ORGANIZATION OF THE UNITED

NATIONS - FAO. Animal Feed

Resources Information System. A6 Andropogon gayanus Kunth.

Disponível em: <http://www.fao.org/ag/AGA/AGAP/F RG/afris/es/Data/21.HTM>. Acesso em: 29 out. 2012.

LACERDA, M.S.B.; ALVES, A.A.; OLIVEIRA, M.E.; ROGÉRIO, M.C.P.; CARVAHO, T.B.; VERAS, V.S.

Composição bromatológica e produtividade do capim-andropógon em diferentes idades de rebrota em sistema silvipastoril. Acta Scientiarum.

Animal Sciences, v.31, n.2, p.123-129, 2009.

FATHI, N.M.H.; DANESH, M.M.; FRANCE, J.; CANT, J.P.; KEBREAB, E. Evaluation of models to describe ruminal degradation kinetics from in situ ruminal incubation of whole soybeans. Journal of Dairy Science, v.89, n.8, p.3087-3095, 2006.

NATIONAL RESEARCH COUNCIL NRC. Nutrient requirements of dairy cattle. Washington, D.C.: National Academy Press, 2001. 381p.

ØRSKOV, E.R.; McDONALD, I. The estimation of protein degradability in the rumen from incubation measurements weighted according to rate of passage. Journal of Agricultural Science, v.92, n.2, p.499503, 1979.

RODRIGUES, A.L.P.; SAMPAIO, I.B.M.; CARNEIRO, J.C. et al. Degradabilidade in situ da matéria seca de forragens tropicais obtidas em diferentes épocas de corte. Arquivo Brasileiro de Medicina Veterinária e Zootecnia, v.56, n.5, p.658-664, 2004. 
SAMPAIO, I.B.M.; PIKE, D.J.;

OWEN, E. Optimal design for studying dry matter degradation in the rumen.

Arquivo Brasileiro de Medicina Veterinária e Zootecnia, v.47, n.3, p.373-383, 1995.

\section{STATISTICAL ANALYSIS SYSTEM}

INSTITUTE. Statistical analysis system user's guide. Version 8. Cary: SAS Institute, 2000.

SILVA, D.J.; QUEIROZ, A.C. Análise de Alimentos: métodos químicos e biológicos. 3.ed. Viçosa: Universidade Federal de Viçosa, 2002. 235p.

SOUZA, G.B.; NOGUEIRA, A.R.A.; SUMI, L.M.; BATISTA, L.A.R.

Método alternativo para a determinação de fibra em detergente neutro e detergente ácido. São Carlos: Embrapa Pecuária Sudeste, 1999. 21p. (Boletim de Pesquisa, 4).
VASCONÇELOS, W.A.; SANTOS, E.M.; ZANINE, A.M.; PINTO, T.F.; LIMA, W.C.; EDVAN, R.L.; PEREIRA, O.G. Valor nutritivo de silagens de capim-mombaça (Panicum maximum Jacq.) colhido em função de idades de rebrotação. Revista Brasileira de Saúde e Produção Animal [online], v.10, n.4, p.874-884, 2009.

VERAS, V.S.; OLIVEIRA, M.E.; LACERDA, M.S.B.; CARVALHO, T.B.; ALVES, A.A. Produção de biomassa e estrutura do pasto de capimandropogon em sistema silvipastoril e monocultura. Arquivo Brasileiro de Medicina Veterinária e Zootecnia, v.61, n.1, p.200-207, 2010.

Data de recebimento: 19/07/2013

Data de aprovação: 25/08/2014 